\title{
Efeito do glicerol, etilenoglicol, acetamida e leite desnatado na criopreservação de espermatozóides eqüinos
}

[Effects of glycerol, ethylene glycol, acetamide, and dried skim milk in cryopreservation of equine sperm]

\author{
G.C. Juliani, M. Henry \\ Escola de Veterinária - UFMG \\ Caixa Postal 567 \\ 30123-970 - Belo Horizonte, MG
}

\begin{abstract}
RESUMO
Avaliou-se a eficácia de diferentes associações de crioprotetores no congelamento de sêmen eqüino. Foram utilizados três ejaculados de oito garanhões para testar o diluidor lactose-EDTA-gema de ovo com as seguintes associações de macromoléculas e crioprotetores: T1 - glicerol 5\% (controle); T2 - metilcelulose $0,5 \%$, rafinose $0,15 \mathrm{~g}$ e acetamida $2,5 \%$; T3 - metilcelulose $0,5 \%$, rafinose $0,15 \mathrm{~g}$ e acetamida $3,5 \%$; T 4 - metilcelulose $0,5 \%$, rafinose $0,15 \mathrm{~g}$ e acetamida 5\%; T5 - glicerol 5\% e 2,4g de leite desnatado; T6 - 1\% de glicerol, 4\% de etilenoglicol e 2,4g de leite desnatado; $\mathrm{T} 7-5 \%$ de etilenoglicol e 2,4g de leite desnatado. $\mathrm{O}$ sêmen foi diluído em meio Kenney (1:1), centrifugado a $400 \mathrm{x}$ g por 12 minutos, ressuspendido nos diluidores para atingir a concentração de $100 \times 10^{6} / \mathrm{ml}$, envasado em palhetas de $0,5 \mathrm{ml}$ e congelado $3 \mathrm{~cm}$ acima do nível de nitrogênio líquido por 10 minutos. $\mathrm{O}$ descongelamento foi realizado em banho-maria a $75^{\circ} \mathrm{C}$ por sete segundos. Após o descongelamento foram avaliados: motilidade total e progressiva, vigor, morfologia espermática e integridade estrutural e funcional da membrana plasmática. O T1 apresentou os maiores valores de motilidade total e progressiva (38,4\% e 33,8\%, respectivamente). O vigor e os resultados do teste HO não diferiram entre os tratamentos. Os diluidores contendo leite em sua composição (T5, T6 e T7) apresentaram maiores valores de integridade funcional e estrutural da membrana plasmática. Pode-se concluir que as modificações incorporadas aos meios diluidores testados não resultaram em melhor efeito crioprotetor que o meio à base de glicerol $5 \%$ no congelamento do sêmen eqüino.
\end{abstract}

Palavras-chave: eqüino, sêmen, crioprotetor, criopreservação

\begin{abstract}
The efficacy of different combinations of cryoprotectants for equine semen was evaluated. Three ejaculates of eight stallions were used to test the lactose-EDTA-egg yolk extender with the following association of cryoprotectants: $T 1$ - glycerol 5\% (control group); T2 - methyl cellulose $0.5 \%$, raffinose $0.15 \mathrm{~g}$, and acetamide 2.5\%; T3 - methyl cellulose $0.5 \%$, raffinose $0.15 \mathrm{~g}$, and acetamide $3.5 \%$; T4 - methyl cellulose $0.5 \%$, raffinose $0.15 \mathrm{~g}$, and acetamide 5\%; T5 - glycerol 5\% and $2.4 \mathrm{~g}$ of dried skim milk; T6 - glycerol 1\%, ethylene glycol 4\%, and $2.4 \mathrm{~g}$ of dried skim milk; T7 - ethylene glycol 5\% and $2.4 \mathrm{~g}$ of dried skim milk. After collection, Kenney extender was added to the semen 1:1, and centrifuged at $400 x \mathrm{~g}$ for 12 minutes. Sperm pellets were diluted to reach $100 \times 10^{6}$ cells $/ \mathrm{ml}$. Spermatozoa were frozen in $0.5 \mathrm{ml}$ straws $3 \mathrm{~cm}$ above the nitrogen level, during 10 minutes. Thawing of samples was done at $75^{\circ} \mathrm{C}$ for seven seconds followed by immersion of the straw in a water bath at $37^{\circ} \mathrm{C}$ for 30 seconds. Post-thaw total and progressive motilities and sperm vigor were evaluated. Sperm membrane integrities of the tail and caput, respectively, were evaluated by the hypoosmotic swelling test and fluorescent dyes. T1 showed the highest post-thaw total and progressive motilities (38.4\% and 33.8\%, respectively). No significant difference was found among treatments for vigor and hypoosmotic swelling test. T5, T6, and T7 showed higher post-thaw values for sperm membrane integrity. It may be concluded that the association of cryoprotectants used in this experiment did not result in better cryoprotectant effect than $5 \%$ glycerol for equine semen cryopreservation.
\end{abstract}

Keywords: equine, semen, cryoprotectant, cryopreservation

Recebido em 5 de dezembro de 2007

Aceito em 2 de setembro de 2008

E-mail: geraldo.juliani@fead.br 


\section{INTRODUÇÃO}

Nos últimos anos, cresceu o interesse e o uso do sêmen eqüino congelado, em razão dos altos custos e das dificuldades e transtornos do transporte dos eqüinos e do estímulo provocado pela legalização do uso do sêmen congelado por parte de várias associações de raças. Aliado a isso, houve o surgimento de novas tecnologias de inseminação artificial nesta espécie proporcionando melhoria na eficiência do uso de sêmen congelado e fomentando o estudo e as pesquisas na criopreservação de sêmen eqüino. No entanto, apesar de a primeira prenhez obtida pós-inseminação artificial com sêmen congelado ter ocorrido há quase meio século (Barker e Gandier, 1957), os protocolos de congelamento não foram capazes até hoje de manter sêmen congelado que resultasse em taxas de prenhez satisfatórias.

Com o objetivo de melhorar a preservação da integridade celular, a associação de agentes crioprotetores tem sido amplamente utilizada nos meios de congelamento de sêmen eqüino, como, por exemplo, a do glicerol à gema de ovo (Samper et al., 1991), ou ao leite desnatado (Burns e Reasner, 1995). Além desses, outros crioprotetores, como etilenoglicol, acetamida e diferentes moléculas, como trealose, metilcelulose e rafinose, têm sido incorporados (Alvarenga et al., 2000; Cottorello, 2002; Henry et al., 2002). Diferentes modificações nos meios diluidores têm sido testadas, porém a melhora, expressa em ganhos de fertilidade do sêmen congelado, ainda é muito discreta e inconsistente, deixando plenamente aberta e atual a necessidade de melhorar as técnicas de congelamento nesta espécie. Dessa forma, este trabalho teve por objetivo estudar meios diluidores alternativos e testar novas associações de crioprotetores e macromoléculas, com o intuito de melhorar a manutenção das estruturas e funções espermáticas pós-descongelamento.

\section{MATERIAL E MÉTODOS}

Foram utilizados oito garanhões da raça Mangalarga Marchador, com idade entre três e 23 anos. Os garanhões tiveram suas reservas espermáticas extragonadais equilibradas, por meio de coletas de sêmen, durante sete dias consecutivos. Três dias após o equilíbrio das reservas extragonádicas, foi iniciado o período de congelamento. Foram coletados três ejaculados de cada garanhão, com um intervalo de dois dias entre as coletas.

Após as coletas, os ejaculados foram filtrados, e a fração do ejaculado livre de gel foi avaliada in natura, quanto às características físicas do sêmen, e imediatamente diluída em igual volume (1:1), em meio diluidor Kenney (Kenney et al., 1975) sem antibiótico (pH 6,77; 349,5mOsm), pré-aquecido a $37^{\circ} \mathrm{C}$. Após a diluição, o sêmen foi dividido em sete alíquotas e mantido à temperatura ambiente durante 30 minutos, antes de ser centrifugado. As alíquotas foram centrifugadas a $400 \mathrm{x}$ g por 12 minutos. Depois de centrifugado, foi retirado o sobrenadante e o sedimento foi inicialmente ressuspendido na proporção de 1:2 no meio crioprotetor em teste, e a diluição final foi realizada para atingir a concentração de $100 \times 10^{6}$ espermatozóides $/ \mathrm{ml}$. $\mathrm{O}$ sêmen foi envasado em palhetas de cloreto polivinílico de $0,5 \mathrm{ml}$. O congelamento foi realizado colocando as palhetas a $3 \mathrm{~cm}$ sobre o vapor de nitrogênio líquido durante 10 minutos, submergindo-as, e estocando-as, em seguida, em nitrogênio líquido.

Foram testadas sete diferentes associações de crioprotetores, utilizando como meio diluidor base a solução lactose-EDTA-gema de ovo (Martin et al., 1979), sendo determinados os seguintes tratamentos $(\mathrm{T}): \mathrm{T} 1=$ diluidor base + $5 \%$ de glicerol, (pH 6,39; 1073mOsm) - controle; $\mathrm{T} 2=$ diluidor base $+0,5 \%$ de metilcelulose, $0,15 \mathrm{~g}$ de rafinose e 2,5\% de acetamida ( $\mathrm{pH}$ 6,34; $813,5 \mathrm{mOsm}) ; \mathrm{T} 3=\mathrm{T} 2+3,5 \%$ de acetamida $(\mathrm{pH}$ $6,34 ; 987,5 \mathrm{mOsm}) ; \mathrm{T} 4=\mathrm{T} 2+5 \%$ de acetamida (pH 6,29; 1126mOsm); $\mathrm{T} 5=\mathrm{T} 1+2,4 \mathrm{~g}$ de leite

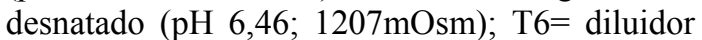
base $+1 \%$ de glicerol e $4 \%$ de etilenoglicol, acrescido de 2,4g de leite desnatado ( $\mathrm{pH} \mathrm{6,52;}$ $1384 \mathrm{mOsm})$ e $\mathrm{T} 7=$ diluidor base $+5 \%$ de etilenoglicol, acrescido de $2,4 \mathrm{~g}$ de leite desnatado ( $\mathrm{pH} 6,50 ; 1370,5 \mathrm{mOsm})$. A escolha destes tratamentos foi baseada em experimentos prévios do grupo de pesquisa.

$\mathrm{O}$ descongelamento foi realizado submergindo as palhetas em banho-maria a $75^{\circ} \mathrm{C}$ por sete segundos, seguidos de imersão em banho-maria a $37^{\circ} \mathrm{C}$ por 30 segundos.

As motilidade total e progressiva foram analisadas em microscopia óptica com aumento 
de 400x, entre lâmina e lamínula, previamente aquecida a $37^{\circ} \mathrm{C}$. Somente foram congelados ejaculados que, após permanecerem 30 minutos no meio de centrifugação, apresentaram espermatozóides com motilidade progressiva superior a $50 \%$. O vigor do movimento dos espermatozóides foi classificado de zero (ausente) a cinco (máximo). Não foram congelados ejaculados com concentração espermática in natura abaixo de $60 \times 10^{6}$ espermatozóides/ml.

A morfologia espermática foi avaliada em amostra de sêmen preservada em solução de formol-salina tamponada (Barth e Oko, 1989), em microscopia de contraste de fase.

A avaliação da integridade funcional da membrana plasmática da cauda dos espermatozóides foi feita pelo teste hiposmótico (HO), realizado pela diluição de $50 \mu \mathrm{l}$ de sêmen em $0,5 \mathrm{ml}$ de solução de sacarose a $100 \mathrm{mOsmol} / 1$, ambos a $37^{\circ} \mathrm{C}$, seguido de incubação em banhomaria a $37^{\circ} \mathrm{C}$ por 30 minutos e fixação com $0,5 \mathrm{ml}$ de solução de formol salina tamponada para posterior análise em microscopia de contraste de fase. $\mathrm{O}$ valor do teste $\mathrm{HO}$ foi expresso em percentual e calculado segundo Melo et al. (2005).

A coloração de fluorescência foi utilizada pósdescongelamento para avaliar a integridade estrutural da membrana plasmática e acrossomal da cabeça dos espermatozóides. Utilizou-se o protocolo proposto por Harrison e Vickers (1990), modificado por Zuccari (1998), no qual dois fluorocromos foram usados: o diacetato de carboxifluoresceína e o iodeto de propídio ${ }^{1}$. As amostras foram incubadas à temperatura ambiente durante três horas em sala escura, sendo subseqüentemente avaliadas, ao abrigo da luz, em microscópio de fluorescência, utilizando filtros de 480 a $610 \mathrm{~nm}$.

Para análise estatística, foi realizada uma análise de variância considerando o delineamento em blocos ao acaso e os garanhões como bloco. As médias foram comparadas pelo teste Duncan, com exceção da variável vigor que foi avaliada pelo teste Kruskal-Wallis.

\section{RESULTADOS E DISCUSSÃO}

Os resultados de motilidade espermática e vigor pós-descongelamento encontram-se na Tab. 1. Os resultados obtidos foram semelhantes aos valores encontrados na literatura para sêmen eqüino congelado (Vidament et al., 1997; Papa et al. e Dell Aqua Jr., 2001; Vidament et al., 2002; Juliani e Henry, 2006). Para a motilidade total pós-descongelamento, não foi observado diferença entre os tratamentos $(\mathrm{P}>0,05)$.

A motilidade progressiva pós-descongelamento do $\mathrm{T} 1$ foi mais alta $(\mathrm{P}<0,05)$ que a dos demais tratamentos, exceto em relação ao T7 que, estatisticamente igual ao $\mathrm{T} 1$, não diferiu dos demais tratamentos $(\mathrm{P}>0,05)$.

A adição do leite desnatado ao T5 provocou significativa diminuição no valor da motilidade progressiva. Henry et al. (2002), ao avaliarem a motilidade progressiva pós-descongelamento, verificaram, para os diluidores à base de $1 \%$ glicerol e $4 \%$ etilenoglicol, etilenoglicol 5\% e glicerol 5\%, motilidade progressiva de 33,3\%; $32,0 \%$ e $36,2 \%$, respectivamente. Ecot et al. (2000), Dell Aqua Jr. e Papa (2001) sugeriram melhora na criopreservação para a associação do leite desnatado ao crioprotetor. Nesse experimento, a associação do leite desnatado aos diluidores à base de glicerol $5 \%$, de etilenoglicol $5 \%$ e de associação de $1 \%$ de glicerol e $4 \%$ de etilenoglicol não proporcionou ganhos na motilidade progressiva dos espermatozóides de eqüinos após descongelamento. A associação de crioprotetores, além das modificações do meio diluidor, implica outras alterações impostas aos espermatozóides, como, por exemplo, mudanças de osmolaridade. Neste trabalho, a adição de $2,4 \mathrm{~g}$ de leite desnatado provocou alteração de osmolaridade de $1073 \mathrm{mOsmol}$ do T1 para $1207 \mathrm{mOsmol}$ no T5. Griggers et al. (2001) consideraram a condição de hiperosmolaridade como fator prejudicial à sobrevivência dos espermatozóides de bovinos. De acordo com Carmo et al. (2005), as variações de osmolaridade durante as etapas do processo de criopreservação podem resultar em alterações e lesões na membrana plasmática dos espermatozóides.

\footnotetext{
${ }^{1}$ Sigma, St. Louis, EUA.
} 
Tabela 1. Motilidade e vigor médio pós-descongelamento de espermatozóides de oito garanhões, congelados em sete meios diluidores

\begin{tabular}{lccc} 
Tratamento & MT $(\%)$ & MP $(\%)$ & V $(0-5)$ \\
\hline T1 & $38,4 \pm 9,1 \mathrm{a}$ & $33,9 \pm 7,8 \mathrm{a}$ & $2,9 \pm 0,4 \mathrm{a}$ \\
T2 & $27,9 \pm 9,9 \mathrm{a}$ & $19,8 \pm 9,9 \mathrm{~b}$ & $2,2 \pm 0,5 \mathrm{a}$ \\
T3 & $31,9 \pm 8,4 \mathrm{a}$ & $24,5 \pm 11,1 \mathrm{~b}$ & $2,5 \pm 0,3 \mathrm{a}$ \\
T4 & $28,7 \pm 8,9 \mathrm{a}$ & $22,5 \pm 5,2 \mathrm{~b}$ & $2,6 \pm 0,5 \mathrm{a}$ \\
T5 & $30,0 \pm 9,3 \mathrm{a}$ & $24,5 \pm 8,9 \mathrm{~b}$ & $2,5 \pm 0,4 \mathrm{a}$ \\
T6 & $25,1 \pm 6,2 \mathrm{a}$ & $22,9 \pm 11,0 \mathrm{~b}$ & $2,6 \pm 0,5 \mathrm{a}$ \\
T7 & $34,7 \pm 6,0 \mathrm{a}$ & $27,3 \pm 9,4 \mathrm{ab}$ & $2,7 \pm 0,4 \mathrm{a}$ \\
\hline
\end{tabular}

MT: motilidade total; MP: motilidade progressiva; V: vigor, média de três ejaculados por garanhão. T1: diluidor base, $5 \%$ de glicerol (controle). T2: diluidor base, $0,5 \%$ de metilcelulose, $0,15 \mathrm{~g}$ de rafinose e 2,5\% de acetamida. T3: T2 + $3,5 \%$ de acetamida. T4: T2 $+5 \%$ de acetamida. T5: $\mathrm{T} 1+2,4 \mathrm{~g}$ de leite desnatado. T6: diluidor base com $1 \%$ de glicerol e $4 \%$ de etilenoglicol, 2,4g de leite desnatado. T7: diluidor base, $5 \%$ de etilenoglicol, 2,4g de leite desnatado. Médias com letras diferentes na coluna diferem entre si $(\mathrm{P}<0,05)$.

T2, T3 e T6 apresentaram, após o descongelamento, valores menores de motilidade total e progressiva. Keith et al. (2000) também observaram queda na motilidade espermática pós-descongelamento, quando compararam diluidores à base de acetamida, em relação ao glicerol. Medeiros et al. (2002), ao utilizarem um crioprotetor a base de leite, relataram maiores valores de motilidade total e progressiva para a acetamida que para o glicerol. Henry et al. (2002) associaram a acetamida à trealose e à metilcelulose, encontrando para esta associação maiores valores de motilidade progressiva pósdescongelamento em comparação a outros tratamentos estudados. Aisen et al. (2002) relataram que a trealose tem se mostrado mais efetiva na criopreservação do que a rafinose. Essa melhor ação da trealose em comparação a outros dissacarídeos pode ser devido a uma crioproteção específica exercida sobre a bicamada lipídica da membrana. Dell Aqua Jr. e
Papa (2001) demonstraram que o meio Kenney preservaria as características espermáticas tão bem quanto outros meios de centrifugação, no entanto os efeitos da interação desse meio com a acetamida, a rafinose e a metilcelulose sobre os espermatozóides não são conhecidos. Para o vigor espermático, os resultados obtidos mostraram não haver diferença $(\mathrm{P}>0,05)$ entre os tratamentos.

$\mathrm{Na}$ Tab. 2, observa-se que o $\mathrm{T} 1$ apresentou número de espermatozóides normais pósdescongelamento inferior $(\mathrm{P}<0,05)$ aos valores encontrados para os demais tratamentos. Apesar disso, os valores encontrados ainda permaneceram dentro dos padrões considerados aceitáveis para o sêmen eqüino (Osório et al., 2006; Clulow et al., 2007). Nos demais tratamentos, não foi identificado meio mais eficaz na preservação dessa variável $(\mathrm{P}>0,05)$.

Tabela 2. Porcentagem média de espermatozóides (Sptz) morfologicamente normais e reativos ao teste hiposmótico (HO), pós-descongelamento de sêmen de garanhões criopreservado em sete diferentes diluidores

\begin{tabular}{ccc}
\hline Tratamento & HO reativo (\%) & Sptz normais (\%) \\
\hline T1 & $25,3 \pm 9,0 \mathrm{a}$ & $60,2 \pm 5,3 \mathrm{~b}$ \\
T2 & $24,2 \pm 9,2 \mathrm{a}$ & $65,8 \pm 6,1 \mathrm{a}$ \\
T3 & $24,0 \pm 7,1 \mathrm{a}$ & $65,4 \pm 7,3 \mathrm{a}$ \\
T4 & $23,9 \pm 5,1 \mathrm{a}$ & $64,1 \pm 7,7 \mathrm{a}$ \\
T5 & $27,9 \pm 13,6 \mathrm{a}$ & $62,9 \pm 7,2 \mathrm{ab}$ \\
T6 & $30,9 \pm 14,2 \mathrm{a}$ & $62,8 \pm 6,9 \mathrm{ab}$ \\
T7 & $29,3 \pm 8,4 \mathrm{a}$ & $64,8 \pm 7,3 \mathrm{a}$ \\
\hline
\end{tabular}

Média de três ejaculados de oito garanhões. T1: diluidor base, $5 \%$ de glicerol (controle). T2: diluidor base, $0,5 \%$ de metilcelulose, $0,15 \mathrm{~g}$ de rafinose e $2,5 \%$ de acetamida. T3: T2 $+3,5 \%$ de acetamida. T4: $\mathrm{T} 2+2,5 \%$ de acetamida. T5: $\mathrm{T} 1+2,4 \mathrm{~g}$ de leite desnatado. T6: diluidor base, $1 \%$ de glicerol e $4 \%$ de etilenoglicol, $2,4 \mathrm{~g}$ de leite desnatado. T7: diluidor base, $5 \%$ de etilenoglicol, 2,4g de leite desnatado. Médias com letras diferentes na coluna diferem entre si $(\mathrm{P}<0,05)$. 
A porcentagem média de espermatozóides reativos ao teste $\mathrm{HO}$ (Tab. 2) foi semelhante às encontradas na literatura para o sêmen eqüino congelado (Osório et al., 2006; Juliani et al., 2007; Clulow et al., 2007). Nos resultados do teste de HO, houve apenas uma variação. T5, T6 e T7 apresentaram maior número de espermatozóides reativos ao $\mathrm{HO}$, enquanto $\mathrm{T} 2$, T3 e T4 menores valores de espermatozóides reativos ao HO. Henry et al. (2002), ao usarem as mesmas concentrações de acetamida, porém substituindo a rafinose pela trealose, também não observaram diferença $(\mathrm{P}>0,05)$ entre os tratamentos. T5, T6 e T7 foram tratamentos com leite desnatado, sugerindo que o leite pode, de alguma forma, contribuir na preservação da integridade funcional da membrana plasmática da cauda dos espermatozóides criopreservados.

A avaliação da integridade funcional das membranas plasmática e acrossomal permitiu identificar diferença $(\mathrm{P}<0,05)$ entre os tratamentos. A população de células semi-lesadas não diferiu substancialmente entre os tratamentos. T5, T6 e T7 foram os que apresentaram maiores percentuais de espermatozóides íntegros pós-descongelamento. $\mathrm{E}$ interessante ressaltar que todos estes tratamentos apresentavam o leite desnatado em sua composição (Tab. 3).

Tabela 3. Porcentagem de espermatozóides eqüinos íntegros, semi-lesados e lesados pósdescongelamento, criopreservados em meio diluidor com sete diferentes composições de crioprotetores

\begin{tabular}{cccc}
\hline Tratamento & Íntegro (\%) & Semi-lesado (\%) & Lesado (\%) \\
\hline T1 & $55,0 \pm 13,8 \mathrm{ab}$ & $28,2 \pm 8,0 \mathrm{bc}$ & $14,9 \pm 6,4 \mathrm{bc}$ \\
T2 & $44,7 \pm 6,7 \mathrm{c}$ & $35,7 \pm 7,7 \mathrm{a}$ & $19,6 \pm 7,2 \mathrm{ab}$ \\
T3 & $52,0 \pm 9,6 \mathrm{abc}$ & $32,2 \pm 7,7 \mathrm{abc}$ & $15,8 \pm 5,2 \mathrm{abc}$ \\
T4 & $46,5 \pm 8,0 \mathrm{bc}$ & $33,3 \pm 8,3 \mathrm{ab}$ & $20,6 \pm 6,2 \mathrm{a}$ \\
T5 & $61,4 \pm 7,2 \mathrm{a}$ & $27,4 \pm 7,5 \mathrm{bc}$ & $11,1 \pm 5,0 \mathrm{c}$ \\
T6 & $58,9 \pm 7,1 \mathrm{a}$ & $26,8 \pm 7,6 \mathrm{c}$ & $14,3 \pm 3,6 \mathrm{bc}$ \\
T7 & $57,3 \pm 6,0 \mathrm{a}$ & $28,8 \pm 5,5 \mathrm{bc}$ & $14,0 \pm 4,9 \mathrm{bc}$ \\
\hline \hline
\end{tabular}

Média de três ejaculados de oito garanhões. T1: diluidor base, $5 \%$ de glicerol (controle). T2: diluidor base, $0,5 \%$ de metilcelulose, $0,15 \mathrm{~g}$ de rafinose e $2,5 \%$ de acetamida. T3: $\mathrm{T} 2+3,5 \%$ de acetamida. T4: $\mathrm{T} 2+2,5 \%$ de acetamida. T5: $\mathrm{T} 1+2,4 \mathrm{~g}$ de leite desnatado. T6: diluidor base, $1 \%$ de glicerol e $4 \%$ de etilenoglicol, $2,4 \mathrm{~g}$ de leite desnatado. T7: diluidor base, $5 \%$ de etilenoglicol, 2,4g de leite desnatado. Médias com letras diferentes na coluna diferem entre si $(\mathrm{P}<0,05)$.

Ao se comparar os resultados de T1 e T5, que utilizaram o glicerol 5\% como crioprotetor, observa-se aumento no número de espermatozóides íntegros, de 55,0\% (T1) para $61,4 \%$, quando o leite desnatado foi acrescido ao glicerol 5\% (T5). Estes resultados fortalecem a tendência observada anteriormente para a avaliação de reatividade ao $\mathrm{HO}$, quando os maiores valores ao $\mathrm{HO}$ foram obtidos para tratamentos que continham leite desnatado. Essas observações sugerem que a associação de leite desnatado aos crioprotetores glicerol e etilenoglicol preservaria melhor a integridade estrutural da membrana plasmática dos espermatozóides dos eqüinos, durante o processo de criopreservação. Na literatura, é relatado que o efeito benéfico da adição do leite se manifesta pela melhor preservação da motilidade (Pickett et al., 1975; Heitland et al., 1996). No presente trabalho, o efeito crioprotetor do leite foi principalmente notado na melhor proteção às membranas e não na motilidade.

Do mesmo modo ao $\mathrm{HO}$, os tratamentos com acetamida apresentaram, para a fluorescência, os menores valores de integridade espermática, quando comparados aos demais tratamentos. Estes resultados observados para a avaliação da integridade estrutural dos espermatozóides colocam em questionamento a tendência, anteriormente citada para a motilidade total e integridade funcional da membrana plasmática da cauda dos espermatozóides, de que a associação da rafinose à acetamida e à metilcelulose não protegeria tão bem os espermatozóides contra os danos da criopreservação em comparação à associação trealose, acetamida e metilcelulose. 


\section{CONCLUSÕES}

Não houve, com as modificações incorporadas nos tratamentos, melhora no efeito crioprotetor dos meios quando comparado ao meio lactose/gema com 5\% de glicerol. Ficou evidente que a adição de leite desnatado aos meios trouxe melhor proteção à integridade das membranas e que a acetamida junto com a rafinose foi uma associação que resultou em menor efeito crioprotetor. Novos experimentos devem ser conduzidos para se obter o meio crioprotetor ideal para o sêmen eqüino criopreservado.

\section{REFERÊNCIAS BIBLIOGRÁFICAS}

AISEN, E.G.; MEDINA, V.H.; VENTURINO, A. Cryopreservation and post-thawed fertility of ram semen frozen in different trehalose concentrations. Theriogenology, v.57, p.18011808, 2002.

ALVARENGA, M.A.; LANDIMALVARENGA, F.C.; MOREIRA, R.M. et al. Acrosomal ultrastructure of stallion spermatozoa cryopreserved with ethylenenglicol using two packaging systems. Equine Vet. J., v.32, p.541$545,2000$.

BARKER, C.A.V.; GANDIER, J.C.C. Pregnancy in a mare resulted from frozem epididymal spermatozoa. Can. J. Comp. Med. Vet. Sci., v.21, p.47-51, 1957.

BARTH, A.D.; OKO, R.J. Abnormal morphology of bovine spermatozoa. Ames: Iowa State University, 1989. 284p.

BURNS, P.J.; REASNER D.S. Computerized analysis of sperm motion: effects of glycerol concentration on the cryopreservation of equine spermatozoa. Equine Vet. Sci., v.15, p377-380, 1995.

CARMO, M.T.; PAPA, F.O.; MEDEIROS, A.S.L. et al. Improvement of stallion semen postthaw motility with the association dimethyl formamide and methyl formamide as cryoprotectors. Anim. Reprod. Sci., v.89, p.286288, 2005.

COTTORELlO, A.C.P. Associação de etilenoglicol e glicerol na criopreservação de sêmen eqüino. 2002. 64f. Dissertação (Mestrado)
- Escola de Veterinária, Universidade Federal de Minas Gerais, Belo Horizonte.

CLULOW, J.R.; MAXWELL, W.M.C.; EVANS, G. et al. A comparison of duck and chicken egg yolk for cryopreservation of stallion sperm. Aust. Vet. J., v.85, p.232-235, 2007.

DALIMATA, A.M.; GRAHAM, J.K. Cryopresevation of rabbit spermatozoa using acetamide in combination with trehalose and methyl cellulose. Theriogenology, v.48, p.831841, 1997.

DELL'AQUA JR., J.A.; PAPA, F.O. Efeito de diluentes e da intensidade e tempo de centrifugação, sobre os parâmetros espermáticos para congelação de sêmen eqüino. Rev. Bras. Reprod. Anim., v.25, p.460-462, 2001.

ECOT, P.; VIDAMENT, M.; MORNAC, A. et al. Freezing of stallion semen: interactions among cooling treatments, semen extenders and stallions. J. Reprod. Fertil., v.56, suppl., p.141$150,2000$.

GRIGGERS, S.; PACCAMONTI, D.L.; THOMPSON, R.A. et al. The effects of $\mathrm{pH}$, osmolarity and urine contamination on equine spermatozoal motility. Theriogenology, v.56, p.613-622, 2001.

HARRISON, R.A.P.; VICKERS, S.E. Use of fluorescent probes to assess membrane integrity in mammalian spermatozoa. J. Reprod. Fertil., v.88, p.343-352, 1990

HEITLAND, A.V.; JASKO, D.J. SQUIRES, E.L. et al. Factors affecting motion characteristics of frozen-thawed stallion spermatozoa. Equine Vet. J., v.28, p.47-53, 1996.

HENRY, M.; SNOECK, P.P.N.; COTTORELLO, A.C.P. Post-thaw spermatozoa plasma membrane integrity and motility of stallion semen frozen with different cryoprotectants. Theriogenology, v.58, p.245248, 2002.

JULIANI, G.C.; HENRY, M. Effects of low density lypoproteins and dimethyl formamide in differents freezing rates on equine frozen semen. Anim. Reprod., v.3, p.270, 2006. (Resumo).

JULIANI, G.C.; OSÓRIO, J.P.; LAGARES, M.A. et al. Efeito da adição fracionada da dimetil formamida na criopreservação espermática eqüina. In: CONGRESSO BRASILEIRO DE REPRODUÇÃO ANIMAL, 17., 2007, Curitiba. 
Anais...Belo Horizonte: CBRA, 2007. p.167 (Resumo).

KEITH, S.L.; SQUIRES, E.L.; GRAHAM, J.K. et al. Evaluation of cryoprotectans for the preservation of equine spermatozoa (online). Colorado, Word Wide Web 2000: Disponível em:

$<$ hppt://www.cvmbs.colostate.edu/phisio/abstract /els5.html>. Acessado em: 15 mai. 2007.

KENNEY, R.M.; BERGMAN, R.V.; COOPER, W.L. et al. Minimal contamination techniques for breeding mares: techniques and preliminary findings. In: ANNUAL CONVENTION AMERICAN ASSOCIATION EQUINE PRACTITIONERS, 21., 1975, Boston. Proceedings... Boston: AAEP, 1975. p.327-336.

MARTIN, J.C.; KLUG, E.; GUNZEL, A.R. Centrifugation of stallion semen and its storage in large volume straws. J. Reprod. Fert., v.27, suppl., p.47-51, 1979.

MEDEIROS, A.S.L.; GOMES, G.M.; CARMO, M.T. et al. Cryopreservation of stallion sperm using different amides. Theriogenology, v.58, p.273-276, 2002.

MELO, M.I.V.; HENRY, M.; BEKER, A.R.C.L. Teste hiposmótico para avaliação da viabilidade do sêmen eqüino resfriado com diferentes diluidores. Arq. Bras. Med. Vet. Zootec., v.57, p.757-763, 2005.

OSORIO, J.; HENRY, M.; JULIANI, G.C. Effects of fractioned addition of dimethyl formamide in the viability of cryopreserved stallion semen in different procedures of freezing. Anim. Reprod., v.3, p.269, 2006. (Resumo).

PAPA, F.O.; DELL'AQUA JR., J.A. Efeito do tipo de envasamento e método de descongelação sobre os parâmetros espermáticos e índices de fertilidade de sêmen congelado eqüino. Rev. Bras. Reprod. Anim., v.25, p.458-460, 2001.

PICKETT, B.W.; SULLIVAN, J.J.; BYERS, M.S. et al. Effect of centrifugation and seminal plasma on motility and fertility of stallion and bull spermatozoa. Fertil. Steril., v.26, p.167-174, 1975.

SAMPER, J.C.; HELLANDER, J.C.; CRABO, B.G. Relation between fertility of fresh and frozen stallion semen and its quality measured as sperm motility and with glass wool/sephadex filters. J. Reprod. Fertil., v.44, suppl., p.107-114, 1991.

VIDAMENT, M.; DUPERE, A.M.; JULIENNE, $P$. et al. Equine frozen semen: freezability and fertility field results. Theriogenology, v.48, p.907-917, 1997.

VIDAMENT, M.; DAIRE, C.; YVON, J.M. et al. Motility and fertility of stallion semen frozen with glycerol and/or dimethyl formamide. Theriogenology, v.58, p.249-251, 2002.

ZUCCARI, C.E.S.N. Efeito da criopreservação sobre a integridade estrutural da célula espermática eqüina. 1998. 121f. Tese (Doutorado) - Faculdade de Medicina Veterinária e Zootecnia, Universidade Estadual Paulista, Botucatu, SP. 